\title{
Políticas públicas de incentivo à eficiência energética
}

\author{
LEANDRA ALTOÉ , \\ JOSÉ MÁRCIO COSTA II, \\ DELLY OLIVEIRA FILHO III, \\ FRANCISCO JAVIER REY MARTINEZIV, \\ ADRIANO HENRIQUE FERRAREZ ${ }^{V}$, \\ e LUCAS DE ARRUDA VIANAVI
}

\section{Introdução}

$\mathrm{M}$

UITOS PAÍsES estão enfrentando dificuldades para suprir a demanda crescente de energia de suas populações e, ao mesmo tempo, fornecer recursos energéticos para suprir seu crescimento econômico. Cabe, cada vez mais, ao poder público conhecer o comportamento dos consumidores para criar mecanismos que promovam o uso racional de energia nos diferentes setores e, assim, otimizar o uso de energia pela sociedade (Jannuzzi, 2005).

Mecanismos legais de incentivo à conservação de energia têm sido empregados por vários países para reduzir o consumo de energia e as emissões de gases de efeito estufa. Os Estados Unidos, por exemplo, formularam suas primeiras normas de eficiência energética na década de 1970, quando ocorreu a crise de suprimento de petróleo (Dixon et al., 2010). A União Europeia também começou a formular seus instrumentos legais na mesma época, fixando metas de redução da demanda de energia e de emissão de poluentes, a serem atingidas pelos estados-membros (Fouquet, 2013).

O Brasil começou a formular suas legislações de incentivo à eficiência energética na década de 1980. Segundo Geller et al. (2004), políticas nacionais para aumentar a geração de energia por fontes renováveis e a oferta interna de petróleo têm se mostrado bem-sucedidas. Enquanto políticas nacionais para promover o uso de medidas de eficiência energética, por sua vez, foram moderadamente bem-sucedidas.

Há muito espaço para ampliar a gestão governamental na área de conservação de energia no Brasil, principalmente quanto à criação de instrumentos legais de incentivo à geração descentralizada de energia por fontes renováveis e de incentivo à eficiência energética. Objetivou-se com este trabalho discutir as atuais políticas brasileiras de eficiência energética, bem como desafios e oportunidades associados. 


\section{Marcos regulatórios de incentivo à eficiência energética}

\section{Histórico}

A primeira iniciativa do poder público para incentivar o uso de medidas de eficiência energética em nível nacional ocorreu em 1981, com a criação do Programa Conserve. Esse programa visava promover a conservação de energia na indústria, o desenvolvimento de produtos eficientes e a substituição de energéticos importados por fontes nacionais. No ano seguinte, foi lançado o Programa de Mobilização Energética (PME), caracterizado por um conjunto de ações dirigidas para incentivar o uso de medidas de conservação de energia e, especialmente, substituir derivados de petróleo por fontes renováveis de energia (MME, 2011).

Em 1985, por meio de uma atuação abrangente e coordenada, o Estado brasileiro promulgou a Portaria Interministral n.1.877, dos Ministérios de Minas e Energia e do Ministério da Indústria e Comércio Exterior, que instituiu o Programa Nacional de Conservação de Energia Elétrica (Procel). Sua missão foi promover o uso racional de energia elétrica em todo país e entre suas iniciativas está a criação do Programa Brasileiro de Etiquetagem (Brasil, 1985).

Cinco anos depois, foi instituído o Programa Nacional da Racionalização do Uso de Derivados do Petróleo e do Gás Natural (Conpet), por meio de decreto presidencial, de 18 de julho de 1991. Assim, como o Procel, o Conpet foi criado com a finalidade de estimular o uso racional de recursos energéticos no país, mas focado em fontes de energia não renováveis. O Conpet também atua no âmbito do Programa Brasileiro de Etiquetagem (Brasil, 1991).

Em 1997, pela Lei n.9.478, foi lançada a Política Energética Nacional (PEN) e criados o Conselho Nacional de Política Energética e a Agência Nacional de Petróleo. Nesta lei ficaram determinados os princípios da PEN em relação ao aproveitamento racional das fontes de energia, visando à conservação energética e a preservação do meio ambiente (Brasil, 1997).

No início da década de 2000, foi publicado o principal marco legal na área de eficiência energética no país, a Lei n.10.295/2001, a qual lançou a Política Nacional de Conservação e Uso Racional de Energia. Por esta lei se estabeleceu que o Poder Executivo ficaria responsável em desenvolver mecanismos que promovam a eficiência energética de máquinas e equipamentos fabricados e comercializados e das edificações construídas no país (Brasil, 2001a). No mesmo ano, foi publicado o Decreto n.4.059/2001, ao qual regulamentou a Lei n.10.295/2001 ao estabelecer que "os níveis máximos de consumo de energia, ou mínimos de eficiência energética, de máquinas e aparelhos consumidores de energia fabricados ou comercializados no País, bem como as edificações construídas, serão estabelecidos com base em indicadores técnicos e regulamentação específica a ser fixada nos termos deste Decreto, sob a coordenação do Ministério de Minas e Energia" (Brasil, 2001b). 
Nos anos seguintes, houve avanços relevantes no âmbito do Programa Brasileiro de Etiquetagem (PBE). O governo lançou o programa de certificação de eficiência energética para edifícios comerciais, públicos e de serviços em 2009, e para os edifícios residenciais, em 2010. Em 2009, também foi lançada a certificação de eficiência energética de veículos automotores. Tanto a certificação dos edifícios quantos a dos veículos é feita como parte do PBE, estando a primeira sob responsabilidade do Procel e a segunda, do Conpet.

Outro importante marco regulatório na área de energias renováveis e de eficiência energética foi a Resolução Aneel n.482/2012. Essa resolução instituiu um sistema de compensação de energia elétrica no Brasil (Net Metering), no qual unidades consumidoras com micro ou minigeração distribuída (potência instalada de até $1 \mathrm{MW}$ ), a partir de fonte hidráulica, solar, eólica, biomassa ou cogeração qualificada, podem compensar seu consumo de energia. Ao final do mês, realiza-se o balanço de energia elétrica, com base na energia injetada na rede e na energia consumida. Caso a produção de energia seja maior que o consumo, são gerados créditos que podem ser utilizados em até 36 meses (Aneel, 2012).

Em 2015, a Resolução n.482 foi atualizada pela Resolução da Aneel 687. Por esta última resolução, o período de compensação foi ampliado para 60 meses e o limite de potência instalada por usina foi aumentado para $3 \mathrm{MW}$ para fonte hidrelétrica e $5 \mathrm{MW}$ para outras fontes de energia renováveis e cogeração qualificada. Além disso, foi permitida a inclusão de geração compartilhada no sistema nacional de compensação, caracterizada por um consórcio ou cooperativa de consumidores da mesma área de serviço de distribuição de energia elétrica (Aneel, 2015).

Complementarmente à criação de programas e leis, o lançamento de planos nacionais foi importante medida para apoiar o planejamento e execução de medidas de conservação de energia. Entre os planos mais relevantes que versam sobre o assunto estão o Plano Nacional de Energia 2030 (MME, 2007) e o Plano Nacional de Eficiência energética (MME, 2011), os quais serão apresentados a seguir.

\section{Plano Nacional de Energia 2030}

No Plano Nacional de Energia 2030, PNE 2030 (MME, 2007), é apresentado o potencial de aplicação de medidas de eficiência energética no Brasil, para diferentes cenários macroeconômicos, indicados na Tabela l. Esses cenários foram formulados com base em estimativas de crescimento econômico nacional e internacional nos próximos anos. 
Tabela 1 - Caracterização de cenários macroeconômicos nacionais, para o período de 2005 a 2030

\begin{tabular}{llc}
\hline $\begin{array}{l}\text { Cenários } \\
\text { macroeconômicos }\end{array}$ & $\begin{array}{l}\text { Produtividade } \\
\text { da economia brasileira }\end{array}$ & $\begin{array}{l}\text { Taxa média de crescimento } \\
\text { do consumo nacional } \\
\text { de energia, no período } \\
2005 \text { a 2030 (\% ao ano) }\end{array}$ \\
\hline $\mathrm{A}$ & Elevada & 4,3 \\
$\mathrm{~B}_{1}$ & Média para elevada & 3,6 \\
$\mathrm{~B}_{2}$ & Média para reduzida & 3,1 \\
$\mathrm{C}$ & Reduzida & 2,5 \\
\hline
\end{tabular}

Fonte: MME (2007).

No PNE 2030, o potencial de aplicação de medidas de eficiência energética é analisado para dois tipos de crescimentos da economia: autônomo e induzido. O primeiro refere-se àquele potencial obtido por meio da dinâmica natural de aumento da eficiência, como reposição tecnológica e adequações de hábitos de consumo. O segundo, por sua vez, é referente ao obtido por meio da promulgação de políticas públicas e programas específicos, orientadas para aumentar a conservação do uso da energia. O potencial de eficiência energética por crescimento autônomo é estimado para os setores agropecuário, comercial, público, transportes, industrial e residencial; e o potencial por crescimento autônomo e induzido, para o setor elétrico nacional.

Os potenciais de aplicação de medidas de eficiência energética por crescimento autônomo, apontados no PNE 2030, para diferentes setores e cenários macroeconômicos são apresentados nas Tabelas de 2 a 5.

Tabela 2 - Potencial de aplicação de medidas de eficiência energética por meio de crescimento autônomo para o cenário A, em relação ao ano de 2010

\begin{tabular}{lll}
\hline Setor & $\%$ & \\
\cline { 2 - 3 } & 2020 & 2030 \\
\hline Agropecuário & 5,8 & 10,1 \\
Comercial e Público & 8,0 & 8,0 \\
Residencial & 6,7 & 8,0 \\
Transportes & 7,1 & 13,1 \\
Industrial & 7,9 & 10,7 \\
\hline
\end{tabular}

Fonte: MME (2007). 
Tabela 3 - Potencial de aplicação de medidas de eficiência energética por meio de crescimento autônomo para o cenário Bl, em relação ao ano de 2010

\begin{tabular}{lll}
\hline Setor & $\%$ & \\
\cline { 2 - 3 } & 2020 & 2030 \\
\hline Agropecuário & 3,3 & 6,0 \\
Comercial e Público & 5,1 & 5,8 \\
Residencial & 3,4 & 4,1 \\
Transportes & 6,9 & 12,1 \\
Industrial & 5,8 & 7,9 \\
\hline
\end{tabular}

Fonte: MME (2007).

Tabela 4 - Potencial de aplicação de medidas de eficiência energética por meio de crescimento autônomo para o cenário B2, em relação ao ano de 2010

\begin{tabular}{lll}
\hline Setor & $\%$ & \\
\cline { 2 - 3 } & 2020 & 2030 \\
\hline Agropecuário & 2,6 & 4,6 \\
Comercial e Público & 4,3 & 4,7 \\
Residencial & 3,3 & 3,9 \\
Transportes & 6,6 & 12,0 \\
Industrial & 3,8 & 6,0 \\
\hline
\end{tabular}

Fonte: MME (2007).

Tabela 5 - Potencial de aplicação de medidas de eficiência energética por meio de crescimento autônomo para o cenário C, em relação ao ano de 2010

\begin{tabular}{lll}
\hline Setor/Ano & $\%$ & \\
\cline { 2 - 3 } & 2020 & 2030 \\
\hline Agropecuário & 1,2 & 2,0 \\
Comercial e Público & 2,9 & 3,3 \\
Residencial & 2,5 & 3,4 \\
Transportes & 3,5 & 5,9 \\
Industrial & 3,0 & 4,2 \\
\hline
\end{tabular}

Fonte: MME (2007).

Portanto, verifica-se que, em geral, o potencial de aplicação de medidas de eficiência energética é muito dependente do cenário econômico, quanto maior o crescimento econômico, maior a possibilidade de se conservar a energia empregada. Em 2030, espera-se que o potencial de crescimento dos diferentes setores nacionais variará de $4,4 \%$ a $10,9 \%$ em relação a 2010 . 
Ressalta-se que os potenciais de crescimento apresentados nas Tabelas 2 a 5 são relativamente pequenos, uma vez que consideraram apenas o progresso autônomo, ou seja, sem considerar a economia de energia que pode ser obtida por meio de mecanismos legais de incentivo à eficiência energética (progresso induzido). A exemplo, no próprio PNE 2030, é estimado um potencial de eficiência energética para o setor elétrico nacional de $5 \%$ por progresso autônomo e outros $5 \%$ por progresso induzido. Ao se aproveitar apenas $5 \%$ de potencial de eficiência energética desse setor seria possível economizar cerca de 53 TWh, o que permitiria evitar investimentos em geração de energia elétrica entre US\$ 15 a 18 bilhões, entre 2010 e 2030 (MME, 2007).

\section{Plano Nacional de Eficiência Energética}

O Plano Nacional de Eficiência Energética, PNEf (MME, 2011), descreve ações diversas que podem ser desenvolvidas para aumentar a conservação de energia nos setores industrial, transportes, edificações, iluminação pública, saneamento, educação, entre outros.

Entre as medidas apontadas pelo PNEf para o setor das indústrias está a criação de mecanismos que estimulem os empreendedores a contratar serviços de consultoria em eficiência energética. Além disso, é ressaltado no Plano Nacional de Eficiência Energética a necessidade de modernizar a indústria nacional por meio da adoção de incentivos fiscais para a substituição de equipamentos ineficientes. Outra medida interessante citada é a expansão dos sistemas de cogeração, para aumentar o rendimento dos processos e diminuir os custos financeiros, como o reaproveitamento de resíduos de biomassa e gases de coqueria.

Para o setor dos transportes, o PNEf propõe a efetiva mudança da atual matriz brasileira, de predominante rodoviário para um modelo misto rodoviário, ferroviário e hidroviário. Complementarmente à diversificação da malha de transportes, aborda-se a necessidade de promoção do desenvolvimento tecnológico para melhoria dos motores de veículos, incluindo as opções de motores híbridos e elétricos. Outro ponto ressaltado é a ampliação de Programa Brasileiro de Etiquetagem Veicular (PBE Veicular) para um maior número de tipos e modelos de veículos.

Em relação ao uso de energia em edificações, segundo o Plano Nacional de Eficiência Energética, é necessário investir em capacitação técnica de profissionais da construção civil na área da eficiência energética. Outro ponto fundamental citado é a incorporação de conceitos de eficiência energética nos estudos de planejamento urbano e nos códigos de obras dos municípios brasileiros. Além disso, é abordada a importância de tornar obrigatória a certificação de eficiência energética de edifícios. Em 2014, a certificação tornou-se de caráter mandatório para edifícios públicos federais, estando em caráter voluntário para os edifícios públicos estaduais e municipais, comerciais e residenciais (Brasil, 2014).

Para a iluminação pública, o PNEf aborda a necessidade de maior aplicação do Programa Nacional de Iluminação Pública e Sinalização Semafórica 
Eficientes (Procel Reluz), o qual tem como objetivo implementar medidas de eficiência energética em sistemas de iluminação pública diversos, como rodovias, parques, praças, entre outros. Uma medida complementar citada é a de incentivar a indústria nacional de Light Emitting Diodes (LED) para aplicação desse na iluminação pública, assim como, nos demais setores.

$\mathrm{Na}$ área de saneamento básico, o Plano Nacional de Eficiência Energética aponta a importância de fomentar o desenvolvimento de metodologias de diagnóstico e intervenção nos sistemas de abastecimento e tratamento com foco em eficiência energética, observando a sinergia entre energia e hidráulica. É ressaltada, ainda, a necessidade de ampliar linhas de financiamento para produtos empregados no setor com melhores níveis de eficiência energética. Na área de atuação do $\mathrm{PBE}$, o plano discute a ampliação dos processos de etiquetagem e o selo de eficiência energética de equipamentos sanitários.

Por fim, o PNEf enfatiza a necessidade de trabalhar o tema eficiência energética na educação, nos diferentes níveis de ensino. São apresentados planos para promoção de ações integradas entre escolas e comunidades sobre o combate ao desperdício de energia, de modo que o conhecimento compartilhado na sala de aula possa ser repassado à população. Além disso, é enfatizada a necessidade de expandir os conhecimentos sobre conservação de energia na formação profissional de engenheiros e arquitetos, assim como consolidar a rede de laboratórios de certificação e centros de pesquisa em eficiência energética no país.

\section{Discussão}

Na Figura l é apresentada uma linha do tempo com os principais marcos regulatórios nacionais na área de eficiência energética que foram apresentados.

Entre as principais motivações para a criação da Lei n.10.295/2001, principal marco legal na área eficiência energética, está a crise nacional de energia elétrica ocorrida no mesmo ano. O Brasil superou o racionamento de energia principalmente devido a mecanismos de gestão do lado da demanda, como mudança de hábitos de consumo e substituição de equipamentos menos eficientes. Portanto, é necessário que o poder público crie um planejamento energético estratégico, para que possa atuar de forma efetiva na geração, fornecimento e consumo de energia no país de forma contínua, e não apenas em momento de crises.

De acordo com o Plano Nacional de Energia 2030, existe um potencial médio de aplicação de medidas de eficiência energética na faixa de 2,9\% a 7,3\% para 2020 e $4,4 \%$ a $10,9 \%$ para 2030 , em relação a 2010 , considerando diferentes setores e cenários macroeconômicos nacionais (MME, 2007). Portanto, o potencial de eficiência energética pode variar bastante conforme o desenvolvimento econômico; em geral, quanto maior o crescimento da economia, tanto maior o potencial de aplicações de medidas de conservação de energia. Na Figura 2, são apresentados o potencial médio de eficiência energética para diferentes cenários macroeconômicos e o consumo de energia dos diferentes setores analisados no PNE 2030. 


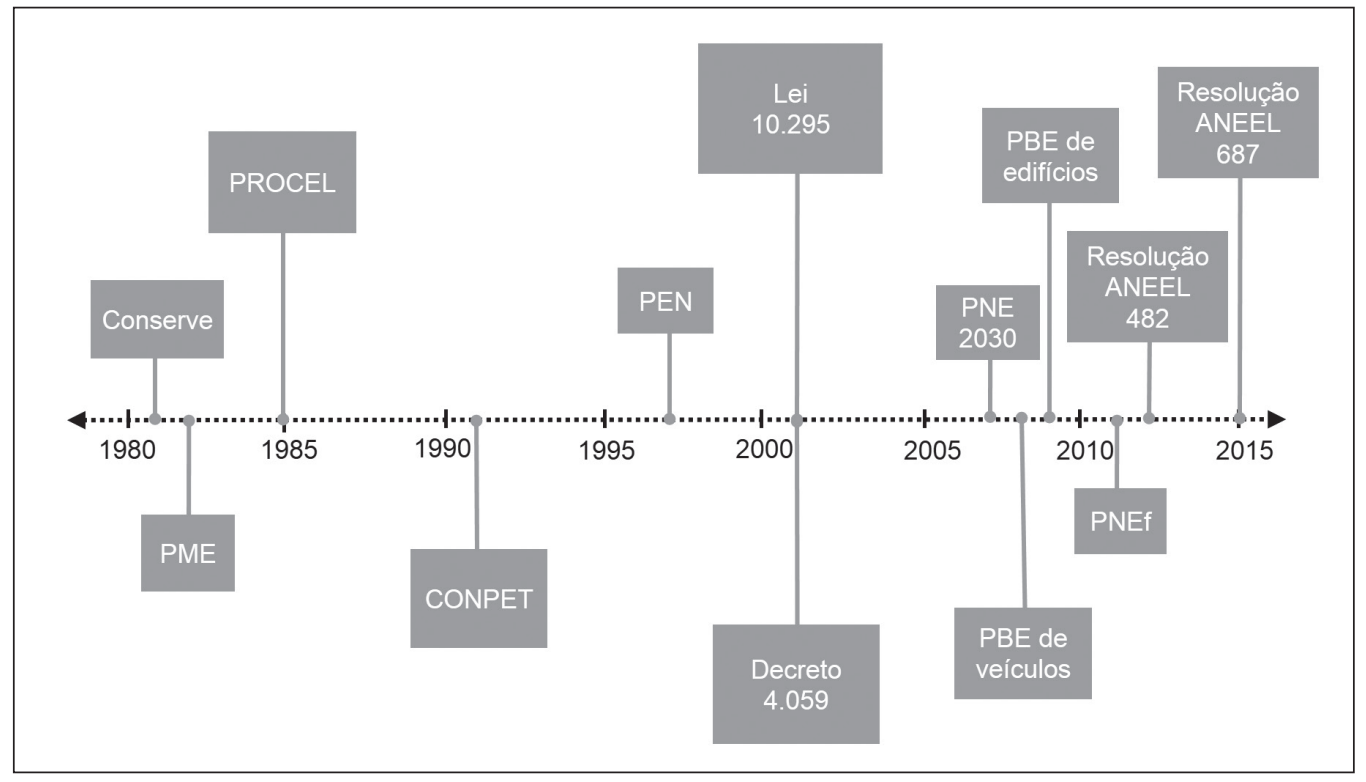

Figura 1 - Linha do tempo dos principais marcos regulatórios brasileiros na área de eficiência energética.

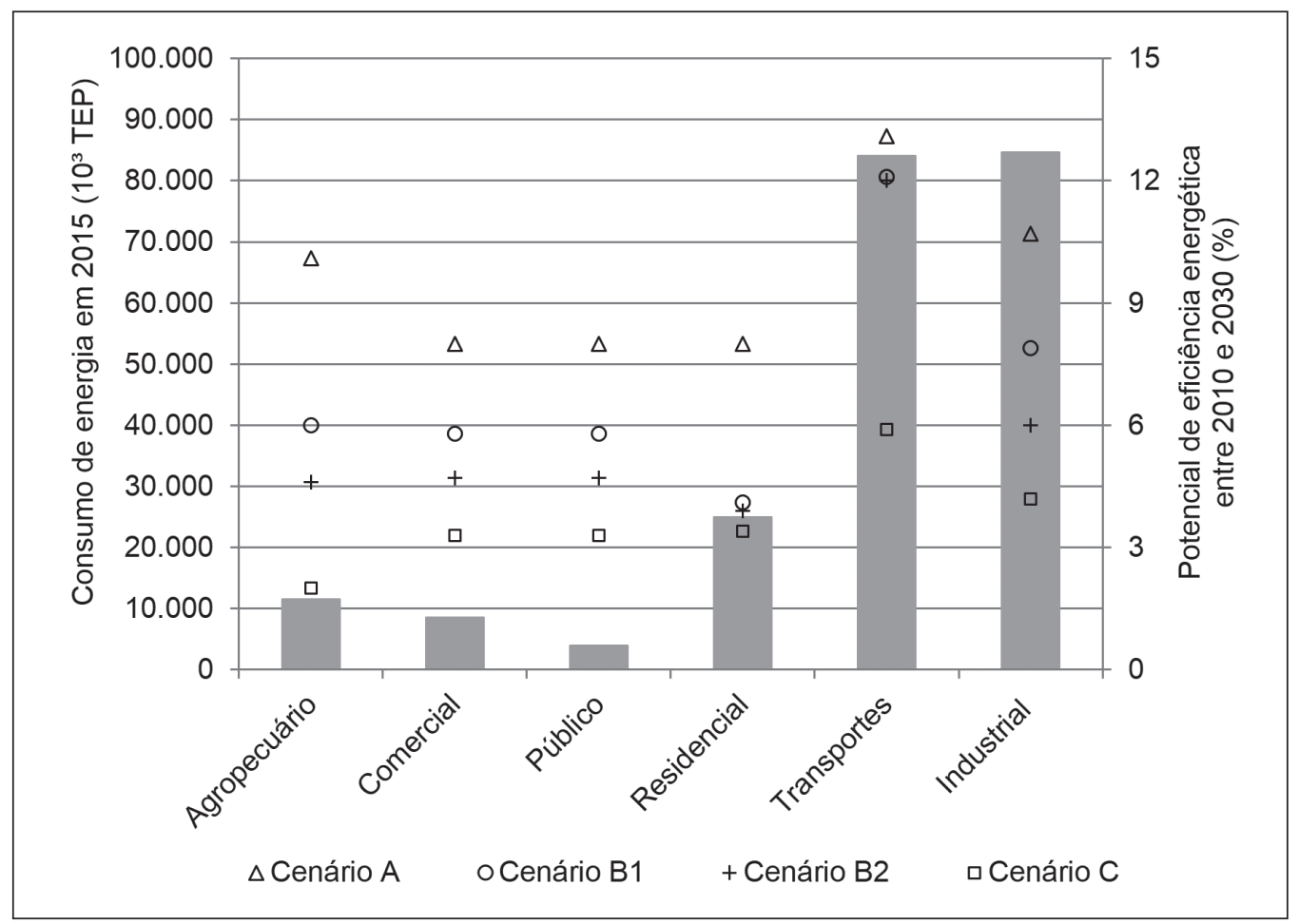

Fonte: EPE (2016); MME (2007).

Figura 2 - Consumo de energia em 2015 versus potencial de eficiência energética por crescimento autônomo entre 2010 e 2030, para diferentes setores e cenários macroeconômicos. 
O setor industrial foi o que apresentou maior consumo de energia e o segundo maior potencial médio de economia caso medidas de eficiência energética sejam aplicadas. Existem várias ações que podem ser adotadas para aumentar o uso racional de energia na indústria, como a utilização de processos e equipamentos mais eficientes. Um dos possíveis modos de implementar essas mudanças é por meio de realização de auditorias energéticas, as quais consistem em analisar as condições de uso de insumos energéticos e identificar oportunidades de melhoria. Em países europeus, como Alemanha e França, os governos oferecem incentivos fiscais para a realização de auditoras energéticas no setor industrial (Fleiter et al., 2012). Tal modelo poderia ser estudado e implementado no Brasil, de modo a promover a conservação de energia em diferentes segmentos produtivos.

O setor de transportes apresentou o segundo maior consumo de energia e o maior potencial de economia caso medidas de eficiência energética sejam aplicadas. Entre as principais ações que podem ser aplicadas no setor está a diversificação da malha nacional de transportes. É preciso reparar as rodovias e, principalmente, reativar as ferrovias e criar vias navegáveis para melhorar a qualidade e a eficiência energéticas do escoamento da produção. Como consequência, haveria diminuição de custos e aumento de competitividade no mercado internacional. Além disso, é imprescindível o desenvolvimento de veículos mais eficientes e a expansão do uso de biocombustíveis, como etanol e biodiesel.

Dentre os setores estudados, o setor agropecuário apresentou o quarto maior consumo de energia e o terceiro maior potencial de economia caso medidas de eficiência energética sejam aplicadas. Esse setor merece ser analisado de forma cuidadosa, não apenas do ponto de vista de consumo de energia, mas também de água. De acordo com a FAO (2012), atualmente, a agricultura responde por $70 \%$ de toda a água apropriada para uso humano. $\mathrm{O}$ uso de sistemas de irrigação localizada, como microaspersão e gotejamento, além de reduzir o consumo de energia, demanda menor quantidade de água. Isto principalmente é importante neste momento atual, em que várias regiões do Brasil estão passando por uma crise hídrica.

Os setores residencial, comercial e de serviços ficaram em terceiro, quinto e sexto lugares, respectivamente, em consumo de energia e apresentaram os menores potenciais médios de economia de energia caso medidas de eficiência energética sejam aplicadas. Todavia, o potencial de redução da demanda de energia desses setores não deve ser ignorado, uma vez que uma série de medidas de conservação de energia pode ser implementada, incluindo: i) certificação energética de edifícios; ii) uso de eletrodomésticos eficientes; iii) geração descentralizada de energia elétrica e térmica por fontes renováveis, como energia eólica, solar fotovoltaica e solar térmica; e iv) promoção de campanhas de conscientização da população quanto ao uso racional de energia. 
O Plano Nacional de Energia 2030 aponta um potencial de eficiência energética para o setor elétrico nacional de $5 \%$ por crescimento autônomo e $5 \%$ por crescimento indutivo. Para atingir tal meta, é necessária inserir medidas de eficiência energética no gerenciamento do lado da oferta e do lado da demanda. No primeiro caso, pode-se trabalhar com conceitos de conservação de energia nas ações de planejamento e de gestão do sistema interligado nacional, e no segundo, formular mecanismos legais de incentivo ao uso de tecnologias eficientes de geração de energia e de combate ao desperdício de energia.

A crise hídrica atual, associada à falta de planejamento de longo prazo, tendo em vista a grande dependência de geração hidráulica na oferta interna de energia elétrica impliou a necessidade de acionar um número de usinas termelétricas expressivo, as quais possuem custo de operação maior que as usinas hidrelétricas (Galvão; Bermann, 2015). Assim, foi constatado que em 2015 no Brasil a participação de fontes renováveis de energia na matriz de energia primária foi de $41,2 \%$, valor inferior ao planejado de $44,0 \%$ no plano Brasil 2030 (EPE, 2016). Nesse contexto, o incentivo ao uso de medidas que promovam a geração descentralizada por meio de fontes renováveis é importante para assegurar o suprimento da demanda de energia do Brasil e aumentar a participação de fontes renováveis na matriz energética.

No Plano Nacional de Eficiência Energética é apresentada uma série de ações com vistas à conservação de energia para os setores analisados pelo Plano Nacional de Energia 2030 (agropecuário, comercial, público, residencial, transportes e industrial) e outros setores, como iluminação pública, saneamento e educação. Portanto, é necessário que o poder público se articule e desenvolva frentes de trabalho, em parceria com os diferentes ministérios e secretarias, para promover o maior uso de medidas de eficiência energética nos diferentes setores produtivos e por parte da população.

Além das medidas previstas no Plano Nacional de Eficiência Energética, outras devem ser exploradas para que seja possível atingir as metas de conservação de energia traçadas no Plano Nacional de Energia 2030. Entre elas, pode-se citar sistema mais agressivo de medidas de incentivo à geração descentralizada de energia, como o Feed-in Tariff, pelo qual os consumidores com geração de energia elétrica por fonte renovável podem vender a energia produzida à concessionária por um preço mais elevado do que o preço de mercado. Esse sistema está em uso em dezenas de países, em nível nacional ou estadual, e tem apresentado bons resultados (Timilsina et al., 2012). Portanto, a implantação do sistema Net Metering no Brasil foi um primeiro passo importante neste sentido, e espera-se que futuramente o atual sistema nacional de compensação possa evoluir para um sistema mais atrativo, gerando-se maior interesse de adesão em território nacional, como o Feed Tariffs, que também é denominado de tarifas premium. 


\section{Conclusões}

O Brasil ainda está aquém de muitos países desenvolvidos, como Estados Unidos e membros da União Europeia, em formulação de políticas públicas de eficiência energética. Tais países podem ser usados como referência para definição de legislações brasileiras futuras. Entre as iniciativas nacionais de incentivo ao uso de medidas de eficiência energética, o Programa Brasileiro de Etiquetagem tem se destacado, avaliando atualmente centenas de produtos, incluindo eletrodomésticos, equipamentos hidrossanitários, edifícios e automóveis.

Para atingir o potencial autônomo de eficiência energética traçado no Plano Nacional de 2030 , que é na faixa entre $4,4 \%$ e $8,7 \%$, em relação aos valores de 2010, será necessário planejamento efetivo para promover o uso racional de insumos energéticos pelos diferentes setores econômicos e pela população em geral. Ressalta-se que esses são potenciais autônomos, ou seja, aqueles esperados na evolução normal do mercado. O potencial técnico é muito superior e passível de aproveitamento por meio da implementação de políticas de incentivo mais agressivas na área de conservação de energia.

Entre as ações que precisam ser desenvolvidas para aumentar a conservação energética ressaltam-se: a modernização da indústria, a diversificação da malha de transportes, a implementação de políticas de combate ao desperdício de energia e de normas de eficiência energética mais rigorosas. Aprimorar os instrumentos legais de incentivo ao uso racional de energia no país, junto a ações que promovam o planejamento de médio e de longo prazos, a diversificação da matriz energética nacional é imprescindível para reduzir o risco de uma escassez de energia no país, como já ocorrido no passado.

\section{Agradecimentos}

Os autores são gratos a UFV, UVa, CNPq e Fapemig pelo apoio para a realização deste trabalho.

\section{Referências}

ANEEL - AGÊNCIA NACIONAL DE ENERGIA ELÉTRICA. Resolução Normativa 482 , de 17 de abril de 2012 , a qual estabelece as condições gerais para o acesso de microgeração e minigeração distribuída aos sistemas de distribuição de energia elétrica, o sistema de compensação de energia elétrica, e dá outras providências. Brasília: Diário Oficial da União, 2012.

Resolução Normativa 687, de 24 de novembro de 2015, a qual altera a Resolução Normativa 482, de 17 de abril de 2012. Brasília: Diário Oficial da União, 2015.

BRASIL. Portaria Interministerial MME/MIC n.1.877, de 30 de dezembro de 1985. Institui o Programa Nacional de Conservação de Energia Elétrica (Procel) e dá outras providências. Brasília: Diário Oficial da União, 1985. 
BRASIL. Decreto presidencial de 18 de julho de 1991. Institui o Programa Nacional da Racionalização do Uso dos Derivados do Petróleo e do Gás Natural (Conpet) e dá outras providências. Brasília: Diário Oficial da União, 1991.

Lei 9.478 , de 6 de agosto de 1997. Dispõe sobre a política energética nacional, as atividades relativas ao monopólio do petróleo, institui o Conselho Nacional de Política Energética e a Agência Nacional do Petróleo e dá outras providências. Brasília: Diário Oficial da União, 1997.

Lei 10.295, de 17 de outubro de 2001. Dispõe sobre a Política Nacional de Conservação e Uso Racional de Energia e dá outras providências. Brasília: Diário Oficial da União, 200la.

Decreto 4.059, de 19 de dezembro de 2001. Regulamenta a Lei n.10.295, de 17 de outubro de 2001, que dispõe sobre a Política Nacional de Conservação e Uso Racional de Energia, e dá outras providências. Brasília: Diário Oficial da União, 2001 b.

Instrução Normativa n.2, de 4 de junho de 2014. Dispõe sobre regras para a aquisição ou locação de máquinas e aparelhos consumidores de energia pela Administração Pública Federal direta, autárquica e fundacional, e uso da Etiqueta Nacional de Conservação de Energia (Ence) nos projetos e respectivas edificações públicas federais novas ou que recebam retrofit. Brasília: Diário Oficial da União, 2014.

DIXON, R. K. et al. US energy conservation and efficiency policies: Challenges and opportunities. Energy Policy, v.11, p.6398-408, 2010.

EPE - EMPRESA BRASILEIRA DE ENERGIA. Balanço Energético Nacional 2016. ano base 2015. Rio de Janeiro, 2016.

FAO - FOOD AND AGRICULTURE ORGANIZATION OF THE UNITED NATIONS. Disambiguation of water statistics. Roma, 2012.

FLEITER, T. et al. Adoption of energy-efficiency measures in SMEs - An empirical analysis based on energy audit data from Germany. Energy Policy, v.51, p.863-75, 2012.

FOUQUET, D. Policy instruments for renewable energy - From a European perspective. Renewable Energy, v.49, p.15-18, 2013.

GALVÃO I. J.; BERMANN, C. Crise hídrica e energia: conflitos no uso múltiplo das águas. Estudos Avançados, v.29, n.84, p.43-68, 2015.

GELLER, H. et al. Policies for advancing energy efficiency and renewable energy use in Brazil. Energy Policy, v.32, n.12, p.1437-50, 2004.

JANNUZZI, G. M. Power sector reforms in Brazil and its impacts on energy efficiency and research and development activities. Energy Policy, v.3, p.1753-62, 2005.

MME - MINISTÉRIO DE MINAS E ENERGIA. Plano Nacional de Energia 2030. Brasília, 2007.

. Plano Nacional de Eficiência Energética. Brasília, 2011.

TIMILSINA, G. R.; KURDGELASHVILI, L.; NARBEL, P. A. Solar energy: Markets, economics and policies. Renewable and Sustainable Energy Reviews, v.16, p.449-65, 2012. 
RESUMO - Políticas públicas de incentivo à conservação de energia têm sido empregadas em vários países, a fim de reduzir o consumo de energia e as emissões de gases de efeito estufa. Objetivou-se com este trabalho analisar as políticas públicas brasileiras de promoção à eficiência energética, bem como desafios e oportunidades relacionados. Experiências têm demonstrado que é imprescindível que o governo formule um planejamento energético estratégico, que contemple medidas de incentivo ao uso racional de energia, tanto na gestão do lado da oferta quanto na do lado da demanda, para reduzir o risco de uma crise energética no país, como já ocorrido no passado recente.

PALAVRAS-ChAVES: Uso racional de energia, Potencial de conservação de energia, Planejamento energético, Instrumentos legais de incentivo.

ABSTRACT - Public policies for energy efficiency have been deployed in several countries to reduce energy consumption and the emission of greenhouse gases. This work aims to analyze Brazilian public policies promoting energy efficiency, as well as related challenges and opportunities. It has been shown that governments must develop strategic energy planning, with measures to promote energy management and generate awareness both to the demand and supply sides of the economy and to reduce the risk of another energy crisis in Brazil, as happened in recent past.

KErWORDS: Energy management, Energy conservation potential, Energy planning, Legal incentive instruments.

Leandra Altoé é doutora em Engenharia Agrícola, Universidade Federal de Viçosa, Viçosa, Minas Gerais. @-leandra.altoe@ufv.br

José Márcio Costa é professor do Departamento de Engenharia Agrícola, Universidade Federal de Viçosa, Viçosa, Minas Gerais. @ - marcio.costa@ufv.br

Delly Oliveira Filhoé professor do Departamento de Engenharia Agrícola, Universidade Federal de Viçosa, Viçosa, Minas Gerais. @-delly@ufv.br

Francisco Javier Rey Martinezé professor do Departamento de Ingeniería Energética y Fluidomecánica da Escuela de Ingenierías Industriales, Universidad de Valladolid, Valladolid, Espanha. @ - rey@eii.uva.es

Adriano Henrique Ferrarezé professor do Instituto Federal Fluminense, Itaperuna, Rio de Janeiro. @- aferrarez@iff.edu.br

Lucas de Arruda Vianaé mestrando em Engenharia Agrícola, Universidade Federal de Viçosa, Viçosa, Minas Gerais. @- lucas.viana@ufv.br

Recebido em 18.10.2016 e aceito em 24.11.2016.

I, II, III e VI Centro de Ciências Agrárias, Departamento de Engenharia Agrícola e Ambiental, Universidade Federal de Viçosa, Viçosa, Minas Gerais / Minas Gerais, Brasil.

IV Escuela de Ingenierías Industriales, Universidad de Valladolid, Valladolid, Espanha.

v Instituto Federal de Educação, Ciência e Tecnologia Fluminense, Itaperuna / Rio de Janeiro, Brasil. 